\title{
Correlation between radiographic signs of third molar proximity with inferior alveolar nerve and postoperative occurrence of neurosensory disorders. A prospective, double-blind study ${ }^{1}$
}

\author{
Fábio Wildson Gurgel CostaI, Erick Helton Lima Fontenele ${ }^{\mathrm{II}}$, Tácio Pinheiro Bezerra ${ }^{\mathrm{III}}$, Thyciana Rodrigues Ribeiro ${ }^{\mathrm{IV}}$, Bárbara \\ Gressy Duarte Souza Carneirov, Eduardo Costa Studart Soares ${ }^{\text {VI }}$

\begin{abstract}
IAssistant Professor, Division of Stomatology and Oral Surgery, Campus Sobral, UFC, Fortaleza-CE, Brazil. Conception, design, intellectual and scientific content of the study, manuscript writing, critical revision.

IIDDS, Division of Oral Surgery, Dentistry Cearense College, Fortaleza-CE, Brazil. Acquisition of data, scientific content of the study, manuscript writing.

IIIPhD, Staff, Division of Oral Surgery, Walter Cantidio University Hospital, Fortaleza-CE, Brazil. Conception, design, intellectual and scientific content of the study, manuscript writing, critical revision.

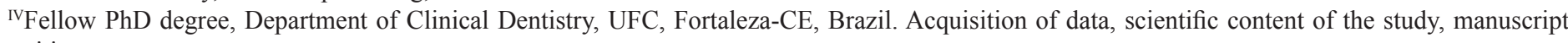
writing.

${ }^{\mathrm{v}}$ DDS, Division of Oral Surgery, Walter Cantidio University Hospital, Fortaleza-CE, Brazil. Conception, design, intellectual and scientific content of the study, manuscript writing, critical revision.

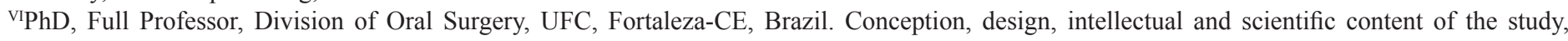
manuscript writing, critical revision.
\end{abstract}

\begin{abstract}
PURPOSE: To evaluate the interference of radiographic factors in the appearance of sensory deficit related to inferior alveolar nerve (IAN) after third molars (3Ms) removal.

METHODS: A prospective, double-blind, observational, unicentric study was performed with 126 patients submitted to a surgical procedure of lower 3Ms removal in the period from March to October/2011. Collected data included gender, age, eruption stage of $3 \mathrm{Ms}$, position/angle of 3Ms (Pell-Gregory and Winter classifications, respectively), presence/absence of radiographic signs of 3Ms proximity with the inferior alveolar canal and surgical technique. Occurrence evaluation of the IAN injury was performed on the seventh postoperative day through pin-prick, two-point discrimination and brush directional stroke tests.

RESULTS: Predominant radiographic signs were: narrowing of the inferior alveolar canal (68.25\%), darkening of root (46.82\%) and diversion of the canal (31\%). None of the patients presented sensory loss. Sixty-one (48.41\%) of the cases had at least one or two radiographic signs of proximity with NAI. Forty-seven (37.3\%) had 3 or more signs, and 18 (14.29\%) did not have any radiographic signs of proximity to mandibular canal.
\end{abstract}

CONCLUSION: There was not a positive correlation between presence of radiographic signs of 3Ms with IAN proximity and postoperative neurosensory disorders occurrence.

Key words: Third molar. Paresthesia. Mandibular Nerve. Panoramic radiography. 


\section{Introduction}

In recent years, several aspects related to surgical removal of third molars ( $3 \mathrm{Ms}$ ) have been discussed, especially the possibility of postoperative complications such as nerve injuries ${ }^{1,2}$. Clinically, neurosensory disorders related to inferior alveolar nerve (IAN) can be manifested as pain, anesthesia, paresthesia, or a combination of these conditions. Among the commonly performed dental procedures, IAN injury is not an uncommon complication ${ }^{3}$, being potentially related to anesthesia for nerve block, endodontic treatment and surgery to remove $3 \mathrm{Ms}^{4}$.

The preoperative radiographic evaluation has been considered as having a potential capacity to predict possible IAN injuries during a surgical procedure. Panoramic radiography is a commonly complementary exam used in the treatment plan for impacted teeth removal, being useful in the evaluation of surgical difficulty degree, third molars morphology and position, operative risks and proximity to adjacent vital structures, such as IAN $^{4}$. Certain radiographic signs often associated with damage to IAN can be observed in panoramic radiographs ${ }^{5}$.

Since prior knowledge about the $3 \mathrm{Ms}$ positioning is of great importance for surgical planning and because of the controversy about the predictability of IAN damage from the third molar position, the present study aimed to conduct a clinical and radiographic prospective study about the risk of IAN neurosensorial deficit after surgeries for lower $3 \mathrm{Ms}$ removal. To date, few studies have described an incidence of IAN injury less than $1 \%{ }^{6-12}$.

\section{Methods}

A prospective, double-blind, observational, unicentric pilot study was performed with patients from the postgraduate program in Oral and Maxillofacial Surgery of the Ceara Federal University in the period from March to October/2011. The study was approved by the ethics committee from UFC, Brazil under protocol number 130/11.

The following formula was used for sample calculation ${ }^{13}$ :$$
\mathrm{n}=\frac{1}{\frac{\mathrm{d}_{\max }^{2}}{Z_{\alpha / 2}^{2} \times \frac{\mathrm{N}_{\mathrm{x} x \mathrm{Q}} \mathrm{Q}}{\mathrm{N}-1}}+\frac{1}{\mathrm{~N}}}
$$

Thus, after calculation we obtained a sample (n) of 132 patients, with a confidence interval of $95 \%$ and a sampling error of $7 \%$. One right or left third molar was removed from each patient.

The study included patients having panoramic radiography who were candidates for removal of one third molar, with age up to 60 years old, without systemic problems, and who accepted to participate in this study after reading the free and clarified consent term. Patients with associated pain, pericoronitis, edema, hyperthermia, limited mouth opening, pre-existing systemic disease and any patologic process related to $3 \mathrm{Ms}$, as well as pregnant or nursing women and surgical procedures with more than two hours of duration were excluded from this study.

\section{Preoperative data collection}

In addition to demographic variables (gender and age), radiographic data was collected from panoramic radiographs. Intraobserver agreement was obtained by computing kappa coefficient. Radiographic interpretation was performed in dark using the same negatoscopy and one magnifying glass. The analyzed radiographic variables were:

1 - Eruption stage: total bone inclusion and partial bone inclusion; semi-inclusion and erupted.

2 - Horizontal and vertical positions according to PellGregory classification ${ }^{14}$.

3 - Angulation of the third molar according to Ma'aita and Alwrikat ${ }^{16}$ that reffers to the angle formed between dental long axis and occlusal plane: Horizontal $<20^{\circ}$; Mesioangular $=20-80^{\circ}$, Vertical $=80-100^{\circ}$; Distoangular $\geq 100^{\circ}$.

4 - Relation of third molar proximity to the mandibular canal according to Félez-Gutiérrez et al. ${ }^{5}$ classification modified by Gomes ${ }^{17}$ : A) darkening of root tips; B) reflection of root tips, C) narrowing of root tips; D) bifid root tips resting on the mandibular canal; E) deviation of the mandibular canal; F) narrowing of the mandibular canal; G) root apex in island.

\section{Surgical procedure}

Regarding surgical technique, it was standardized and performed in an outpatient setting under local anesthesia with appropriate instruments, following strict standards of biosecurity control. All patients were operated by six dentists specialized in surgery with professional experience of about five years (mean 4.3 years) at $3 \mathrm{Ms}$ surgery. Practitioners were instructed to record the time of surgery. 


\section{Evaluation of sensory deficit after surgery}

In the postoperative period of seven days the presence/ absence of neurosensory disorders, as well as any important information reported by the patient were investigated. Postoperative neurosensory disorders were measured through pin-prick (Figure 1), two-point discrimination (Figure 2) and brush directional stroke tests (Figure 3). Patients were instructed to remain with their eyes closed during tests ${ }^{18,19}$. Collection of postoperative data was performed by a professional who did not know if the removed tooth presented radiographic sign of IAN proximity. Furthermore, tests were considered of predictive value when positive results were less than $60 \%$ of testes ${ }^{17}$.

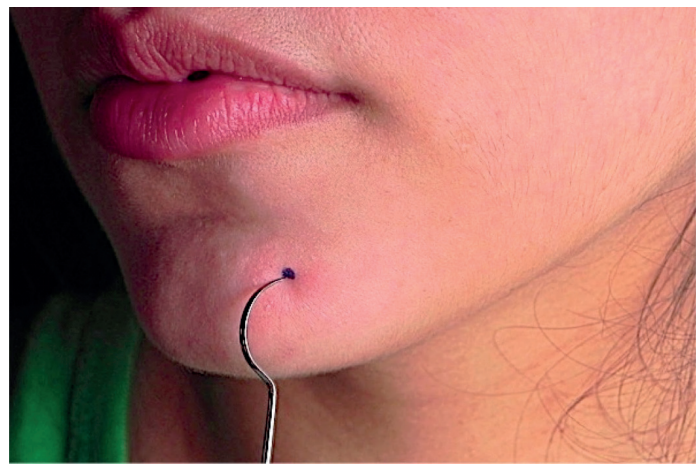

FIGURE 1 - Pin-prick test to measure postoperative neurosensory disorders.

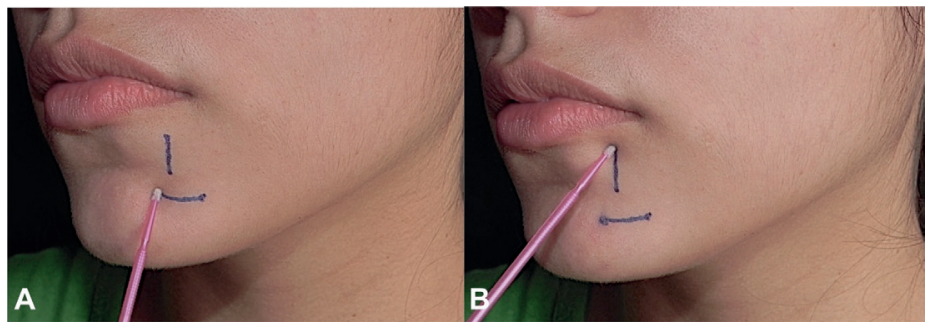

FIGURE 2 - (A, B) Two-point discrimination test to measure postoperative neurosensory disorders.

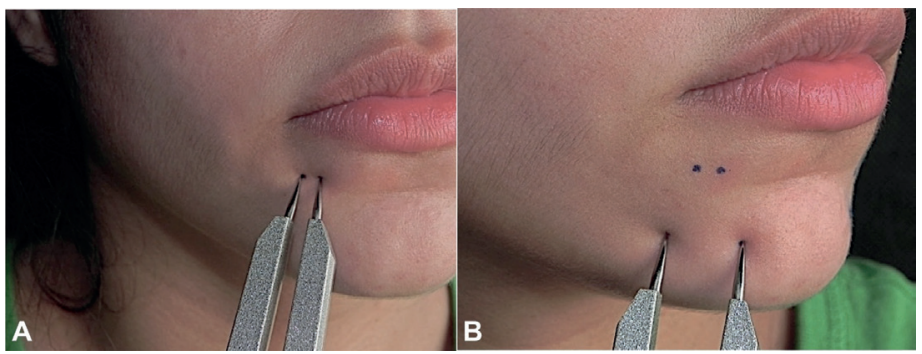

FIGURE 3 - (A, B) Brush directional stroke test.

Pin-prick test consisted of repeating ten touches with an explorer tip on the chin skin and perform how many times the patient accused the contact ${ }^{18}$. Brush directional stroke test consisted of performing ten horizontal and/or vertical movements with a microbrush tip on the chin area and ask for the patient to reproduce the movements ${ }^{18}$. Two-point discrimination test consisted in ten repetitions of the compass application with ends gradually but disorderly separated, so that patients can distinguish the sensitivity of one or two points ${ }^{18}$.

\section{Data analysis}

Data was encoded and tabulated through the software Microsoft ${ }^{\circledR}$ Excel version 2010. Data was subjected to statistical analysis with the software Statistic Package for Social Sciences ${ }^{\circledR}$ (SPSS), version 17.0 for Windows ${ }^{\circledR}$. Descriptive statistics (mean, median and standard deviation) and data frequency were performed. Kolmogorov-Smirnov test was used to check normality of the variables. Chi-square or Fisher's exact test was performed to analyze the association of the variables, when a variable had less than five observations. Mann-Whitney and Krukal Wallis tests were used to compare the mean of ages. In addition, a logistic regression model was used to evaluate variables that could influence the proximity relation of lower third molar with mandibular canal. For this analysis, it was used the likelihood ratio test. In this test, the chi-square statistic was the difference in -2 log-likelihoods between the final model and a reduced model formed by omitting an effect on the final model. Furthermore, the null hypothesis was that all the parameters of this effect were 0 . Statistical significance adopted for all tests was $5 \%(\mathrm{p}<0.05)$.

\section{Results}

From 132 patients enrolled in the sample, six failed to attend the follow-up appointment and were removed from this study. The final sample consisted of $32(25.39 \%)$ male patients and 94 (74.61\%) female patients (Table 1). According to age, 45 patients $(35.71 \%)$ were between 21 and 25 years and 35 patients (27.78\%) were between 16 and 20 years (Table 1$)$. 
TABLE 1 - Distribution of patients according to gender, age and inclusion degree of the lower third molar.

\begin{tabular}{|c|c|c|c|c|c|c|c|c|c|c|c|c|}
\hline \multirow{3}{*}{$\begin{array}{c}\text { Age } \\
\text { (years) }\end{array}$} & \multicolumn{4}{|c|}{ Gender* } & \multicolumn{8}{|c|}{ Inclusion degree of the lower $3 \mathrm{M}^{* *}$} \\
\hline & \multicolumn{2}{|c|}{ Female } & \multicolumn{2}{|c|}{ Male } & \multicolumn{2}{|c|}{ Total } & \multicolumn{2}{|c|}{ Partial } & \multicolumn{2}{|c|}{$\begin{array}{c}\text { Semi- } \\
\text { included }\end{array}$} & \multicolumn{2}{|c|}{ Erupted } \\
\hline & $\mathrm{n}$ & $\%$ & $\mathrm{n}$ & $\%$ & $\mathrm{n}$ & $\%$ & $\mathrm{n}$ & $\%$ & $\mathrm{n}$ & $\%$ & $\mathrm{n}$ & $\%$ \\
\hline$<=15$ & 7 & 5.56 & 4 & 3.17 & 1 & 0.79 & 8 & 6.35 & --- & --- & 2 & 1.59 \\
\hline 16 a 20 & 21 & 16.67 & 14 & 11.11 & 4 & 3.17 & 23 & 18.26 & 6 & 4.76 & 2 & 1.59 \\
\hline 21 a 25 & 33 & 26.19 & 12 & 9.52 & --- & --- & 14 & 11.11 & 16 & 12.71 & 15 & 11.90 \\
\hline 26 a 30 & 25 & 19.84 & 2 & 1.59 & 1 & 0.79 & 11 & 8.73 & 6 & 4.76 & 9 & 7.14 \\
\hline$>30$ & 8 & 6.35 & --- & --- & --- & --- & 1 & 0.79 & 2 & 1.59 & 5 & 3.97 \\
\hline Total & 94 & 74.61 & 32 & 25.39 & 6 & 4.75 & 57 & 45.24 & 30 & 23.82 & 33 & 26.19 \\
\hline
\end{tabular}

$* \mathrm{p}=0.017 ; * * \mathrm{p}=0.001$

The distribution of patients according to eruption stage and degree of bone inclusion of the $3 \mathrm{Ms}$ is present in Table 1 . There was a higher prevalence of teeth with partial bone inclusion (57 patients, $45.24 \%$ ), followed by erupted teeth (33 cases, $26.19 \%$ ) and semi-included teeth (30 cases, 23.82\%).

According to the classification of Pell-Gregory ${ }^{14}$ in relation to horizontal position of $3 \mathrm{Ms}$, most of the teeth was classified as Class 1 (50\%), followed by teeth in Class $2(47.62 \%)$ and only $2.38 \%$ in Class 3 (Table 2) In relation of its vertical position, the higher prevalence were teeth in position $\mathrm{B}(48.41 \%$; $\mathrm{p}<0.001)$, followed by teeth in position A (36.51\%). Position C was observed in $15.08 \%$ of cases (Table 2 ).

TABLE 2 - Distribution of the lower 3Ms according to the Winter (angulation) and Pell-Gregory (horizontal and vertical) classifications.

\begin{tabular}{|c|c|c|c|c|c|c|c|c|c|c|c|c|}
\hline \multirow{3}{*}{$\begin{array}{c}\text { Winter } \\
\text { (angulation) }\end{array}$} & \multicolumn{6}{|c|}{ Pell-Gregory (Horizontal)* } & \multicolumn{6}{|c|}{ Pell-Gregory (Vertical)** } \\
\hline & \multicolumn{2}{|c|}{ Class 1} & \multicolumn{2}{|c|}{ Class 2} & \multicolumn{2}{|c|}{ Class 3} & \multicolumn{2}{|c|}{ Position A } & \multicolumn{2}{|c|}{ Position B } & \multicolumn{2}{|c|}{ Position C } \\
\hline & $\mathrm{n}$ & $\%$ & $\mathrm{n}$ & $\%$ & $\mathrm{n}$ & $\%$ & $\mathrm{n}$ & $\%$ & $\mathrm{n}$ & $\%$ & $\mathrm{n}$ & $\%$ \\
\hline $\begin{array}{l}\text { Mesio- } \\
\text { angular }\end{array}$ & 20 & 15.87 & 22 & 17.46 & 3 & 2.38 & 4 & 3.17 & 28 & 22.22 & 13 & 10.32 \\
\hline Vertical & 30 & 23.82 & 28 & 22.22 & --- & --- & 37 & 29.37 & 19 & 15.08 & 2 & 1.59 \\
\hline $\begin{array}{l}\text { Disto- } \\
\text { angular }\end{array}$ & 1 & 0.79 & --- & --- & --- & --- & --- & --- & 1 & 0.79 & --- & --- \\
\hline Horizontal & 12 & 9.52 & 10 & 7.94 & --- & --- & 5 & 3.97 & 13 & 10.32 & 4 & 3.17 \\
\hline Total & 63 & 50.00 & 60 & 47.62 & 3 & 2.38 & 46 & 36.51 & 61 & 48.41 & 19 & 15.08 \\
\hline
\end{tabular}

${ }^{*} \mathrm{p}=0.338 ; * * \mathrm{p}<0.001$
According to angulation, as described by Ma'aita and Alwrikat ${ }^{16}$, most of the cases was in vertical position $(46.04 \%)$, followed by teeth in mesioangular (35.71\%) and horizontal position (17.46\%) (Table 2).

The root proximity relation of the $3 \mathrm{Ms}$ with mandibular canal was analyzed according to Félez-Gutiérrez et al. ${ }^{6}$ modified by Gomes ${ }^{17}$. It was observed more frequently the "narrowing of the mandibular canal" ( 86 cases, $68.25 \%$ ), followed by "obscuring of the teeth apices" (59 cases, 46.82\%) (Figure 1). In the present study, $61(48.41 \%)$ of the $1263 \mathrm{Ms}$ had at least one or two radiographic signs of proximity with NAI. Forty-seven $(37.3 \%)$ had three or more signs, and 18 (14.29\%) did not have any radiographic signs of proximity to mandibular canal (Table 3).

TABLE 3 - Distribution of the lower 3Ms according to Pell-Gregory classification and relation with mandibular canal.

\begin{tabular}{|c|c|c|c|c|c|c|c|c|c|c|c|c|}
\hline \multirow{3}{*}{$\begin{array}{l}\text { Relation } \\
\text { with } \\
\text { mandibular } \\
\text { canal (n) }\end{array}$} & \multicolumn{6}{|c|}{ Pell-Gregory 1 (Horizontal)* } & \multicolumn{6}{|c|}{ Pell-Gregory 2 (Vertical)** } \\
\hline & \multicolumn{2}{|c|}{ Class 1} & \multicolumn{2}{|c|}{ Class 2} & \multicolumn{2}{|c|}{ Class 3} & \multicolumn{2}{|c|}{ Class A } & \multicolumn{2}{|c|}{ Class B } & \multicolumn{2}{|c|}{ Class C } \\
\hline & $\mathrm{n}$ & $\%$ & $\mathrm{n}$ & $\%$ & $\mathrm{n}$ & $\%$ & $\mathrm{n}$ & $\%$ & $\mathrm{n}$ & $\%$ & $\mathrm{n}$ & $\%$ \\
\hline 1 a 2 & 28 & 22.22 & 31 & 24.60 & 2 & 1.59 & 25 & 19.84 & 27 & 21.43 & 9 & 7.14 \\
\hline$>3$ & 24 & 19.05 & 22 & 17.46 & 1 & 0.79 & 11 & 8.73 & 30 & 23.82 & 6 & 4.76 \\
\hline $\begin{array}{l}\text { Without } \\
\text { relation }\end{array}$ & 11 & 8.73 & 7 & 5.56 & --- & --- & 10 & 7.94 & 4 & 3.17 & 4 & 3.17 \\
\hline Total & 63 & 50.00 & 60 & 47.62 & 3 & 2.38 & 46 & 36.51 & 61 & 48.42 & 19 & 15.07 \\
\hline
\end{tabular}

$* \mathrm{p}=0.785 ; * *_{\mathrm{p}}=0.037$

The surgical technique (osteotomy/odontoseccion) used for $3 \mathrm{Ms}$ removal did not influence the nerve injury occurrence. From the 126 patients enrolled in the study, osteotomy was used in $83.3 \%$, while in $28.56 \%$, odontoseccion was added to this procedure (Table 4).

TABLE 4 - Distribution between surgical technique and lower $3 \mathrm{M}$ angulation.

\begin{tabular}{ccccc}
\hline \multirow{2}{*}{ Angulation } & \multicolumn{2}{c}{ Osteotomy* } & \multicolumn{2}{c}{ Odontosection** } \\
& Yes $(\%)$ & No $(\%)$ & Yes $(\%)$ & No (\%) \\
\hline Mesial & $42(33.33)$ & $3(2.38)$ & $12(9.52)$ & $33(26.2)$ \\
Vertical & $40(31.75)$ & $18(14.29)$ & $4(3.17)$ & $54(42.86)$ \\
Distal & $22(17.46)$ & $0(0)$ & $20(15.87)$ & $2(1.59)$ \\
Horizontal & $105(83.33)$ & $21(16.67)$ & $36(28.56)$ & $90(71.44)$ \\
\hline
\end{tabular}

$* \mathrm{p}=0.001 ; * * \mathrm{p}<0.001$ 
Through logistic regression, the influence of gender, bone inclusion degree of the third molars (Pell and Gregory classification) and angle in relation of proximity to the mandibular canal were evaluated. It was observed that only gender showed influence, with $\mathrm{p}<0.001$ (Table 5).

TABLE 5 - Multivariate logistic regression analysis of panoramic radiographic signs.

\begin{tabular}{ccccc}
\hline & $\begin{array}{c}\text { Criteria of the } \\
\text { model }\end{array}$ & \multicolumn{3}{c}{ Likelihood-ratio test } \\
\cline { 2 - 5 } Variables & $\begin{array}{c}-2 \text { log } \\
\text { likelihood of } \\
\text { the reduced } \\
\text { model }\end{array}$ & Chi - square & $\begin{array}{c}\text { Degree of } \\
\text { freedom }\end{array}$ & $p$-value \\
\hline Intercept & 156.06 & 0.236 & 2 & 0.889 \\
\hline Gender & 165.94 & 10.124 & 2 & 0.006 \\
\hline $\begin{array}{c}\text { Degree of } \\
\text { Inclusion }\end{array}$ & 156.76 & 0.944 & 2 & 0.624 \\
\hline $\begin{array}{c}\text { Pell-Gregory } \\
\text { (Horizontal) }\end{array}$ & 158.18 & 2.361 & 2 & 0.307 \\
\hline $\begin{array}{c}\text { Pell-Gregory } \\
\text { (Vertical) }\end{array}$ & 156.45 & 0.626 & 2 & 0.731 \\
\hline Angulation & 161.42 & 5.601 & 2 & 0.061 \\
\hline
\end{tabular}

Analyzing results from methods for postoperative paresthesia assessment, it was observed that none of the patients presented any nerve sensitivity alteration, whether temporary or permanent. These results may be compared with published data presented in the Table 6 .

TABLE 6 - Prospective studies about incidence $<1 \%$ of sensorineural injury to IAN after surgery to lower $3 \mathrm{Ms}$ removal.

\begin{tabular}{ccccc}
\hline Author & Year & Country & $\mathrm{n}$ & $\begin{array}{c}\text { Injury to } \\
\text { IAN (\%) }\end{array}$ \\
\hline Goldberg et al. & 1985 & USA & 500 & 0.6 \\
Middlehurst et al. & 1988 & UK & 60 & 0 \\
Obiechina & 1990 & Nigeria & 367 & 0.82 \\
Absi, Shepherd & 1993 & UK & 110 & 0.91 \\
Berge, Boe & 1994 & Norway & 204 & 0.49 \\
Bell & 2004 & UK & 300 & 0 \\
Benediktsdottir et al. & 2004 & Iceland & 388 & 0.52 \\
Present study & 2012 & Brazil & 126 & 0 \\
\hline
\end{tabular}

\section{Discussion}

Third molars position is very important for surgical planning and assessment of the procedure difficulty degree ${ }^{19}$. For the present study, panoramic radiographs were used for topographic evaluation of the $3 \mathrm{Ms}$, considering the effectiveness of this commonly used imaging exam as a tool in assessing risks and possible complications during the surgical removal of $3 \mathrm{Ms}$, especially injury to $\mathrm{NAI}^{20}$. It allows general practitioners and maxillofacial surgeons to obtain an evaluation of the elementary preoperative conditions, such as teeth position and angulation (Pell-Gregory and Winter classifications), proximity of the $3 \mathrm{Ms}$ with the mandibular canal and assessment about root shape and number and bone quality ${ }^{19}$.

Patients with deficits related to NAI often suffer from paresthesia, anesthesia or dysesthesia of the lip, chin or vestibular gum in the affected side $^{3}$. Prevalence of NAI injury has been reported between $0.5 \%$ and $5 \%$ according to some studies ${ }^{20,21}$. Disturbances related to NAI were not observed in any patients after third molar surgery. Analyzing prospective studies involving the $3 \mathrm{Ms}$ removal that had NAI damage incidence inferior to $1 \%$, it was observed only two studies with similar results to the present study (Table 6).

In a recent literature review about prospective studies evaluating risk factors for the occurrence of neurosensorial deficit after $3 \mathrm{Ms}$ surgical removal ${ }^{3}$, statistically significant association was found for some variables, such as eruption stage $(p<0.0001)$, surgical technique $(\mathrm{p}<0.0001)$, and predictive radiographic signs $(p<0.0001)$. Concerning to other investigated variables, the authors did not find any statistically significant association, such as gender $(\mathrm{p}=0.1648)$ and pattern of bone impaction $(\mathrm{p}=0.4632)$. In this study, gender showed statistically significant influence.

Most of the third molars were partially erupted in the present research. Regarding the horizontal classification adopted, the highest found prevalence were teeth in Class 1 and Class 2, with close values ( $50 \%$ and $47.62 \%$, respectively), confirming the study of Inaoka et $a l .^{23}$. According to vertical classification, there was a predominance of B position, different from the results of Szalma et al. ${ }^{20}$.

In relation to angulation as described by Ma'aita and Alwrikat1 ${ }^{16}$, vertical position (46.04\%) was followed by mesioangular angulation (35.71\%), which were different from the results observed by Leung and Cheung ${ }^{3}$ that observed a higher prevalence of mesioangular (45.8\%), followed by horizontal $(11.6 \%)$, vertical $(21.3 \%)$ and distoangulares positions of teeth (21.3\%). Blaeser et al. ${ }^{21}$ did not have association between $3 \mathrm{Ms}$ angulation and risk of IAN injury similar to the results of the present study.

Various surgical procedures have been used for $3 \mathrm{Ms}$ 
removal, including osteotomy and odontossection. Analyzing data obtained from patients classified according to surgical technique following angulation, we found that the use of ostectomy and odontossection was mainly related to teeth with mesial or vertical angulation $(\mathrm{p}<0.01)$. Cheung et al. ${ }^{24}$ performed odontossection in $62 \%$ of cases, especially in teeth with mesial (55\%) and horizontal angulation (39\%). The incidence of IAN injury associated with these procedures was below $1 \%$, which confirms the absence of neurosensory disorders observed in this study.

A condition that must be considered in surgical removal of third molars is the close relationship of teeth with mandibular canal. Several authors suggest considering signs observed on panoramic radiographs ${ }^{24}$. In the present study the evaluation parameter established was the classification of the radiographic sign type described by Félez-Gutierrez et al. ${ }^{6}$ and subsequently modified by Gomes et al. ${ }^{17}$, where it is possible to determine or predict the emergence of the inferior alveolar nerve paresthesia after $3 \mathrm{Ms}$ removal through the analysis of panoramic radiographs.

The presence/absence of risk factors observed in panoramic radiographs is not always accurate, since it is a bidimensional-imaging feature. For better observation of these signs is necessary to obtain an image in three dimensions, such as computed tomography, and thus enable a better and more accurate visualization of anatomical structures related to the third molar. However, it must be considered that computed tomography as a complementary diagnostic feature for impacted teeth surgery has a significant financial value for certain populations and not always is available to every surgeon ${ }^{5}$.

The radiographic sign most often found in this study was the narrowing of the mandibular canal, present in 86 of the 126 studied cases $(68.25 \%$ ), followed by darkening of root tips, present in 59 cases $(46.82 \%)$ and mandibular canal deviation in 39 cases $(31 \%)$. In the literature review conducted by Leung and $\mathrm{Cheung}^{4}$, the incidence of IDN deficit was highest in lower wisdom teeth showing radiographic sign of diversion of ID canal by its root $(30 \%)$, followed by darkening of root $(11.6 \%)$ and deflected root by the ID canal $(4.6 \%)$. These three signs were found to significantly increase the risk of IDN deficit $(p<0.0001)$. Although we have presented a percentage of cases with deviation of the mandibular canal similar to studies of the above mentioned authors, there were no cases of neurosensory deficit after $3 \mathrm{Ms}$ removal. This can be explained because these radiographic signs not always indicate an intraoperative exposure of the inferior alveolar nerve, which is considered by many authors one of the main factors related to increased risk of paresthesia ${ }^{25}$.

Further studies are needed to investigate the occurrence of postoperative neurosensory disturbances in patients showing radiographic signs of proximity to IAN.

\section{Conclusion}

There is no any positive correlation between presence of radiographic signs of $3 \mathrm{Ms}$ proximity with IAN and the occurrence of postoperative neurosensory disorders.

\section{References}

1. Scully C, Wolff A. Oral surgery in patients on anticoagulant therapy. Oral Surg Oral Med Oral Pathol Oral Radiol Endod. 2002;94(1):5764.

2. Rood JP. Permanent damage to inferior alveolar and lingual nerves during the removal of impacted mandibular third molars. Comparison of two methods of bone removal. Br Dent J. 1992;172(3):108-10.

3. Renton T. Prevention of iatrogenic inferior alveolar nerve injuries in relation to dental procedures. SADJ. 2010;65(8):342-4.

4. Leung YY, Cheung LK. Risk factors of neurosensory deficits in lower third molar surgery: an literature review of prospective studies. Int J Oral Maxillofac Surg. 2011;40(1):1-10.

5. Libersa P, Savignat M, Tonnel A. Neurosensory disturbances of the inferior alveolar nerve: a retrospective study of complaints in a 10year period. J Oral Maxillofac Surg. 2007;65(8):1486-9.

6. Félez-Gutierrez J, Berini-Aytés L, Gay-Scoda C. Las lesiones del nervio dentario inferior en el tratamiento quirúrgico del tercer molar inferior retenido: aspectos radiológicos, prognósticos y preventivos. Arch Odontoestomatol. 1997;13(2):73-83.

7. Goldberg MH, Nemarich AN, Marco 2nd WP. Complications after mandibular third molar surgery: a statistical analysis of 500 consecutive procedures in private practice. J Am Dent Assoc. 1985;111(2):277-9.

8. Middlehurst RJ, Barker GR, Rood JP. Postoperative morbidity with mandibular third molar surgery: a comparison of two techniques. J Oral Maxillofac Surg. 1988;46(6):474-6.

9. Obiechina AE. Paresthesia after mandibular third molar extractions in Nigerians. Odontostomatol Trop. 1990;13(4):113-4.

10. Absi EG, Shepherd JP. A comparison of morbidity following the removal of lower third molars by the lingual split and surgical bur methods. Int J Oral Maxillofac Surg. 1993;22(3):149-53.

11. Berge TI, Bøe OE. Predictor evaluation of postoperative morbidity after surgical removal of mandibular third molars. Acta Odontol Scand. 1994;52(3):162-9.

12. Bell CW. Use of dental panoramic tomographs to predict the relation between mandibular third molar teeth and the inferior alveolar nerve. Radiological and surgical findings, and clinical outcome. Br J Oral Maxillofac Surg. 2004;42(1):21-7.

13. Benediktsdottir IS, Wenzel A, Petersen JK, Hintze H. Mandibular third molar removal: risk indicators for extended operation time, postoperative pain, and complications. Oral Surg Oral Med Oral Pathol Oral Radiol Endod. 2004;97(4):438-46.

14. Cochran WG. Sampling techniques. New York: John Wiley \& Sons; 1977.

15. Pell GJ, Gregory BT. Impacted mandibular third molars classification and modified technique for removal. Dental Dig. 1933;39:330.

16. Ma'aita J, Alwrikat A. Is the mandibular third molar a risk factor for mandibular angle fracture? Oral Surg Oral Med Oral Pathol Oral Radiol Endod. 2000;89(2):143-6.

17. Gomes AC, Vasconcelos BC, de Oliveira e Silva ED, da Silva LC. 
Correlation between radiographic signs of third molar proximity with inferior alveolar nerve and postoperative occurrence of neurosensory disorders. A prospective, double-blind study

Lingual nerve damage after mandibular third molar surgery: a randomized clinical trial. J Oral Maxillofac Surg. 2005;63(10):14436.

18. Akal UK, Sayan NB, Aydogan S, Yaman Z. Evaluation of the neurosensory deficiencies of oral and maxillofacial region following surgery. Int J Oral Maxillofac Surg. 2000;29(5):331-6.

19. Poort LJ, van Neck JW, van der Wal KG. Sensory testing of inferior alveolar nerve injuries: a review of methods used in prospective studies. J Oral Maxillofac Surg. 2009;67(2):292-300.

20. Szalma J, Lempel E, Jeges S, Szabó G, Olasz L. The prognostic value of panoramic radiography of inferior alveolar nerve damage after mandibular third molar removal: retrospective study of 400 cases. Oral Surg Oral Med Oral Pathol Oral Radiol Endod. 2010;109(2):294-302.

21. Blaeser BF, August MA, Donoff RB, Kaban LB, Dodson TB. Panoramic radiographic risk factors for inferior alveolar nerve injury after third molar extraction. J Oral Maxillofac Surg. 2003;61(4):41721.

22. Von Arx DP, Simpson MT. The effect of dexamethasone on neurapraxia following third molar surgery. Br J Oral Maxillofac Surg. 1989;27(6):477-80.

23. Inaoka SD, Carneiro SC, Vasconcelos BC, Leal J, Porto GG. Relationship between mandibular fracture and impacted lower third molar. Med Oral Patol Oral Cir Bucal. 2009;14(7):E349-54.

24. Cheung LK, Leung YY, Chow LK, Wong MC, Chan EK, Fok YH. Incidence of neurosensory deficits and recovery after lower third molar surgery: a prospective clinical study of 4338 cases. Int J Oral Maxillofac Surg. 2010;39(4):320-6.

25. Bui CH, Seldin EB, Dodson TB. Types, frequencies, and risk factors for complications after third molar extraction. J Oral Maxillofac Surg. 2003;61(12):1379-89.

26. Tantanapornkul W, Okouchi K, Fujiwara Y, Yamashiro M, Maruoka $\mathrm{Y}$, Ohbayashi $\mathrm{N}$, et al. A comparative cone-beam computed tomography and conventional panoramic radiography in assessing topographic relationship between the mandibular canal and impacted third molars. Oral Surg Oral Med Oral Pathol Oral Radiol Endod. 2007;103(2):253-9.

\section{Correspondence:}

Fábio Wildson Gurgel Costa

UFC-Faculdade de Farmácia e Odontologia

Rua Capitão Francisco Pedro, s/n

60430-170 Fortaleza - CE Brasil

Tel.: (55-85)3366-8232

fwildson@yahoo.com.br

Received: October 25, 2012

Review: December 20, 2012

Accepted: January 21, 2013

Conflict of interest: none

Financial source: none

${ }^{1}$ Research performed at School of Dentistry, Postgraduate Program in Dentistry, Dental Clinic Area, Ceara Federal University (UFC), FortalezaCE, Brazil. 